\title{
LECTURA FEMENINA DEL DISCURSO MACHISTA EN DIANA DE CARLOS FUENTES
}

Nacer Ouabbou

\begin{abstract}
RESUMEN
Esta investigación comienza por elucidar la teoría del suplemento desde su génesis, uno de los recursos del deconstruccionismo derridiano, que es un aporte relevante a las teorías de género. Luego, se hace el análisis de diferentes perspectivas femeninas, tanto de la corriente francesa como de la anglosajona. La teoría del suplemento y las perspectivas feministas constituyen el apoyo teórico para intentar leer como mujer Diana o la cazadora solitaria de Carlos Fuentes. El eje central de este trabajo es el estudio de las zonas ocultas del discurso machista y su forma de construir el sujeto femenino. De esta manera, se destaca la importancia de la perspectiva femenina en el análisis literario.
\end{abstract}

\begin{abstract}
This research starts with an elucidation of the theory of supplement from its genesis, one of the recourse of derridian desconstructionism, wich is an important contribution for the theories of genus. Folowed by an analysis of diferents femenists perspectives, of the french current as well as the anglosaxons one. The theory of supplement and feminists perspectives constitut the theoretical support in order to attempt to read like woman Diana o la cazadora solitaria of Carlos Fuentes. This work focus on study of the occults zones of the machiste discourse and how it formes female character. This way, we relieve the importance of feminist perspective in literatury analysis.
\end{abstract}

En dos partes dividida tengo el alma en confusión: una, esclava a la pasión, y otra, a la razón medida.

Sor Juana Inés de la Cruz

\section{Introducción}

Esta investigación es un desafío. Consiste en un intento por leer como mujer una novela, cuya protagonista es la famosa actriz Diana Soren. Tanto el escritor de Diana o la cazadora solitaria, como el autor de este trabajo somos dos hombres bañados de la cultura occidental, fundamentalmente fálico-machista.

Debido a esta situación y a la naturaleza del objeto de estudio, la pregunta siguiente se impone: ¿Puede un hombre leer como mujer? De ser posible, es necesario aclarar el método de análisis que lo permite. 
El objetivo de este trabajo es analizar el lenguaje machista que caracteriza la novela objeto de estudio, porque el lenguaje es el instrumento con que se construye el sujeto literario, en este caso preciso, el sujeto femenino. Resulta interesante observar que el retrato que hace Carlos Fuentes de Diana, tanto en lo privado, en su calidad de amante, como en lo público, por ser famosa actriz, representa un espejo que refleja la imagen de la mujer pública, pintada en el marco del discurso patriarcal.

Para lograr la meta, se ha recorrido a las perspectivas feministas como apoyo teórico, tales como las diferentes nociones del discurso de la feminidad examinadas en el estudio Crítica literaria feminista de Toril Moi, que ofrece una visión panorámica sobre el tema, Les mots des femmes de Mona Ouzouf, Cuando estalla el silencio de Emilia Macaya, y la inevitable filósofa Simone de Beauvoir. Además, esta investigación se apoya en conceptos como: la lógica del suplemento, el juego de la suplementaridad, formulados por Derrida en el marco del desconstruccionismo como estrategia de lectura.

\title{
La teoría del suplemento de Rousseau a Derrida
}

La teoría del suplemento se inscribe en el contexto general del desconstruccionismo. En palabras de Patricio Peñalver Gómez: "A decir verdad, — deconstrucción— no es una buena palabra, y desde luego no es una palabra bella" (1996: 13). Cabe subrayar que por deconstrucción no se entiende nihilismo o destrucción del buen sentido, sino descomposición de un sistema, por ejemplo el logocentrismo, el etnocentrismo, el sistema lingüístico. Es como un movimiento de búsqueda de la presencia como ausencia, del significado como lo que no significa, de zonas ocultas al margen del discurso.

\begin{abstract}
En efecto, desconstruir parece significar ante todo: desestructurar o descomponer, incluso dislocar las estructuras que sostienen la arquitectura conceptual de un determinado sistema o de una secuencia histórica; también desidimentar los estratos de sentido que ocultan la construcción genética de un proceso significante bajo la objetividad constituida y, en suma, solicitar o inquietar, haciendo temblar su suelo, la herencia no pensada de la tradición metafísica (Peñalver 1996: 17, cursiva nuestra).
\end{abstract}

Las palabras desestructurar y estructuras parecen indicar que desconstruir es, en primera instancia, un gesto estructuralista. En efecto, en Carta a un amigo japonés (1987: 38793), que podría llamarse: reflexión sobre la palabra — desconstrucción-, Derrida señala el contexto heideggeriano del término destruktion o abbau, cuya traducción al francés, déconstruction, es equívoco, ya que implica démolition, annihilation. Pero en su contexto original, desconstruir es un gesto que pone atención a las "estructuras". Se trata de deshacer, descomponer todo tipo de estructuras, lingüísticas, logocéntricas y, sobre todo, la estructura del discurso filosófico. Desconstruir tiene valor en contextos como: escritura, traza, margen, différance, suplemento; la lista queda abierta.

La primera lectura de la Carta parece confundir en vez de esclarecer. Ello se debe tal vez al acondicionamiento del lector que, por tradición, busca el significado que está representado en el texto o por la escritura. A la pregunta: ¿Qué es la desconstrucción?, Derrida responde: nada. Su Carta es más bien una reflexión sobre lo que la desconstrucción no es. 
Ce que la déconstruction n'est pas? Mais tout!

Qu'est-ce que la déconstrutión? Mais rien! (1987: 392).

Al final de la Carta, señala que la palabra desconstruir "no es bella", se puede arriesgar su traducción o interpretación al japonés mediante una substitución, una palabra bella: "¿Cómo traducir un poema, poema?". Para saber lo que impone esa palabra en una cadena de substituciones posibles, "hay que analizar y desconstruir esa situación bien determinada". Para desconstruir el sentido de la época de Rousseau, por ejemplo, Derrida sugiere que el movimiento desconstruccionista ha de surgir y operar desde adentro de esa época. Hay que tomar prestado a la antigua estructura todos sus recursos estratégicos:

Los movimientos de desconstrucción no solicitan las estructuras de afuera. No son posibles y eficaces, no ajustan sus golpes que si habitan esas estructuras... operando necesariamente desde adentro, tomando prestado a la antigua estructura todos los recursos estratégicos. (Derrida 1977: 39, traducción nuestra).

Esta sección se delimita al estudio de la suplementaridad, como uno de los recursos del destruccionismo, en el tejido textual derridiano. Se trata de analizar la lógica del suplemento, sus múltiples usos en De la gramatología y su diseminación en el pensamiento dicotómico de Rousseau. Se indagan los gérmenes de la lógica del suplemento desde sus orígenes y se averigua cómo se presenta en forma textual en la obra de Rousseau. Por eso, habrá que mostrar cómo opera la suplementaridad en las oposiciones naturaleza/cultura, habla/escritura, dentro/fuera, centro/margen. ¿Cuándo y cómo el suplemento es peligroso? Nuestro objetivo es captar el juego de la intertextualidad de Rousseau a Derrida para esclarecer cómo, finalmente, éste plantea la teoría del suplemento.

Para plantear la teoría del suplemento, Derrida parte de una lectura de las zonas ocultas del discurso filosófico del siglo XVIII, con énfasis en el pensamiento dicotómico de Rousseau. Desde la advertencia de De la gramatología, Derrida privilegia un texto "corto y poco conocido", al margen del discurso rousseauniano. Se trata del Ensayo sobre el origen de las lenguas. En efecto, varios especialistas de Rousseau no incluyen ese texto inacabado en sus estudios. Sin embargo, ese Ensayo ocupa un tercio de De la Gramatología, más de 145 páginas, al considerar solamente el capítulo 3 "Genèse et structure de l'Essai sur l'origine des langues". Este Ensayo inacabado fue concebido originalmente como una nota aditiva, al igual que las dieciocho notas suplementarias al Discurso sobre el origen y los fundamentos de la desigualdad entre los hombres, designado por el segundo Discurso para distinguirlo del primer Discurso, o sea el Discurso sobre las ciencias y las artes. Pero la versión original del Ensayo no está incluida en ninguna edición del segundo Discurso. Las diez páginas (según la edición), sobre el origen de las lenguas, incluidas en el segundo Discurso, parecen como un injerto, que no rima con la estructura general del texto. Es muy probable que Rousseau prefiriera incluir sus reflexiones sobre las lenguas, directamente en el texto del segundo Discurso.

Según Derrida el Ensayo fue escrito en diferentes períodos:

El Ensayo sobre las lenguas fue pues primitivamente en 1754, una extensa nota del segundo Discurso; en 1762, se convirtió en una disertación independiente, aumentado y corregido para hacer una réplica a Rameau. Finalmente, en 1763, esta disertación, revisada una última vez, fue dividida en capítulos (1977: 278). 
Derrida consultó ese manuscrito inédito conservado en la biblioteca de Neuchâtel (1977: 244). Este Ensayo inacabado, concebido originalmente como un suplemento, una nota aditiva, al margen, constituye la génesis de la teoría del suplemento. Derrida lo reconoce: "El Ensayo debiendo (devant) describir el nacimiento, el ser naciente (l'être-naissant) del suplemento" (1977: 360).

Además del Ensayo, la estructura binaria parece como la columna vertebral del discurso rousseauniano; su pensamiento ofrece un escenario ejemplar del juego de la suplementaridad. La diferencia entre el hombre natural y el hombre civil es fundamental y de allí toda una serie de oposiciones. Lo que Derrida designa como una cadena de suplementos. Es importante señalar que para estudiar el estado de la naturaleza, Rousseau no recurre al método científico, sino al método hipotético-deductivo, método cuestionado por los etnólogos. Las consideraciones de Rousseau son muy distintas de las investigaciones etnológicas que hace Lévi-Strauss sobre los Nambikwara y otros pueblos sin escritura (1977: 174). Rousseau lo dice con toda claridad: el estado natural "quizás no ha existido nunca" (1972: 23). Más adelante advierte que él no tiene al respecto "más que razonamientos hipotéticos y condicionales" (1972: 31).

Toda la primera parte del segundo Discurso es un estudio construido a partir de un supuesto imaginario. El estado de la naturaleza no es más que una metáfora. Sin embargo, es necesario inventarlo por estrategia, como para comenzar al grado cero de la sociedad, para comprender justamente las estructuras del orden social establecido, con el propósito de desestructurar o descomponer el edificio cultural. Así, Rousseau pone de manifiesto que todas las convenciones sociales no son hijas de la naturaleza, sino obra nuestra; y sostiene que, si bien lo que deriva puramente de la naturaleza es universal y perenne, lo cultural y convencional es particular de cada pueblo, en cada contexto espacio temporal; por consiguiente, no solo se puede cambiar, sino que es preciso cambiarlo. En su afán por reformar la sociedad humana, hasta propone la destrucción de la jerarquización Iglesia/Estado secular ${ }^{1}$. Esto explica la furia del Consejo de Ginebra y la polémica que estalló con la condena de Rousseau y sus obras.

A continuación, se intenta ilustrar en dos columnas, las múltiples oposiciones que caracterizan la concepción rousseauniana del hombre, primero en el estado de la naturaleza, luego, en el estado civil o cultural:

\section{ESTADO DE LA NATURALEZA \\ El hombre se caracteriza por:}

1. Agente libre

2. Perfectible

3. Tranquilo, pacífico

4. Desigualdad física

5. Piadoso

6. Corazón, sensible, inocente

7. Amour de soi/ Amor a sí mismo

8. Necesidades naturales, sencillez

9. Grito natural, habla, oralidad

10. Bondad natural: inocencia original de la humanidad

\section{ESTADO CIVIL/ CULTURAL} El hombre se caracteriza por:

1. Esclavo de convenciones

2. Corruptible, imbécil ${ }^{2}$

3. Angustiado, guerrero

4. Desigualdad política que se caracteriza por las jerarquizaciones sociales

5. Indiferente, cruel

6. Razón, razonable, filósofo

7. Amour-propre/ Amor propio

8. Nuevas complicaciones creadas por la civilización, las ciencias y las artes

9. Lógica del discurso. Escritura

10. Maldad, corrupción, vicio: situación real de la humanidad 
Para los fines de esta sección, sería imposible analizar los detalles de estas diez oposiciones. Además, hacen falta muchas otras. No obstante, sería interesante releer a Rousseau a la luz de Derrida. Delimitaremos el tema al análisis del lenguaje como convención, o sea, el punto 9 (Grito natural, habla, oralidad/ Lógica del discurso, escritura), en otras palabras, la oposición: habla/escritura. Ahora bien, esta oposición no se puede aislar completamente de las otras oposiciones, ya que habla y escritura se entienden en el contexto de una cultura. De allí la necesidad de analizar también la relación naturaleza/cultura y algunas otras oposiciones que de ellas derivan y que constituyen la cadena de suplementos de la cual habla Derrida.

En efecto, toda la primera parte de De la gramatología consiste en la elaboración de la teoría de la secundaridad (secondarité) de la escritura, como un afuera (dehors) del sistema del lenguaje, en relación con el habla o la voz, considerado como el adentro (dedans) en el sistema de las lenguas. (La segunda parte es la aplicación de esta teoría a la época de Rousseau). La escritura es el instrumento externo de la lengua, el habla es su medio interno, que permite el sistema de s'entendre-parler a través de la substancia fónica (1977: 17). Dice Derrida:

La escritura, la letra, la inscripción sensible han sido siempre consideradas por la tradición occidental como el cuerpo y la materia externa al espíritu, al soplo, al verbo y al logos (1977: 52).

Emilia Macaya sostiene la misma tesis:

Dentro de la tradición occidental, el pensamiento ha sido identificado con el habla, con el Verbo, más que con la escritura, determinación que resulta fácilmente atribuible a la metafísica (1992: 25).

La oposición entre dos elementos no es una complementaridad sencilla, es una oposición jerarquizada. En la lógica del suplemento, lo aditivo se convierte en peligroso cuando no solo cumple la función de suplementaridad, sino que se produce la inversión del centro/margen. Así, por ejemplo, Rousseau critica la tiranía de la letra o la escritura que altera el interior natural de la lengua. "Para los gramáticos, el arte de la palabra no es más que el arte de la escritura" (citado por Derrida: 1977: 56). La crítica se dirige sobre todo a La gramática general razonada de Port Royal, que constituye una de las fuentes más directas que hacen que el francés escrito se aleje demasiado del francés hablado.

El habla es natural, es la expresión natural del pensamiento. La escritura se agrega como una forma convencional aditiva para significar el pensamiento, para representarlo. La escritura es un suplemento, en cuanto se agrega como técnica, o arte de la representación del habla. La escritura es necesaria como suplemento del habla: cumple la función de la conservación o de la memorización de la historia y de la capitalización del saber (Derrida 1977: 187). El análisis sería más claro con la gráfica siguiente:

\section{LENGUAJE}

Adentro

Habla

Phonè/Sonido audible
Afuera

Escritura

Grama/Imagen visible

La teoría rousseauniana de la lengua, que Derrida considera funcional, sistemática y estructural (1994: 183), consiste en la secundaridad de la escritura en relación con el habla. El 
lenguaje, a su vez, desde su origen como convención social, es un signo suplementario en cuanto al objeto o la cosa designada. (Por convención se entiende la relación establecida entre un objeto y el sonido fónico que lo designa y le da sentido). Luego de esta convención, Rousseau analiza la primera estructura del lenguaje (1972: 55-59). Todo lo anterior se puede resumir así:

La primera convención es la relación establecida entre:

$$
\text { sonido fónico + cosa designada + idea }
$$

De allí la estructura primitiva del lenguaje:

$$
\text { objeto }+ \text { sonido/gesto }+ \text { sentido }
$$

Después de esta primera convención lingüística comienza el sistema de diferencias, ya que si por naturaleza el objeto A es diferente de B, un tercer objeto es diferente de A y B y es llamado C... y así hasta el infinito. Según Rousseau, los primeros hombres no tenían idea de las partes constitutivas de la lengua (objeto + sonido/gesto = oración completa). El presente del infinitivo era el único tiempo verbal conocido. Así por ejemplo, al articular bien o mal: Querer o beber leche sería una oración completa. Con el verbo comenzó la segunda etapa del desarrollo del lenguaje. Los adjetivos llegaron muy tarde, ya que el adjetivo es un sonido/palabra abstracto.

Hay que subrayar que la primera convención lingüística arriba mencionada es entre la substancia fónica que representa el objeto ausente. De allí que la escritura, como suplemento del habla, es ausencia; no es más que la representación gráfica de la presencia.

La suplementaridad que no es nada, ni presencia ni ausencia, no es ni substancia ni esencia del
hombre. Es precisamente el juego de la presencia y de la ausencia, la apertura de este juego que
ningún concepto de la metafísica o de la ontología puede comprender (Derrida 1977: 347).

En esta cita hay un vacío que requiere introducir como un injerto necesario el término différance. "La différance hace posible la oposición de la presencia y de la ausencia" (Derrida 1977: 206). La différance es el lugar entre la presencia y la ausencia. La relación entre la différance y el suplemento es, en cierta medida, muy estrecha. "La différance originaria es la suplementaridad como estructura" (1977: 238). La différance no existe, no es ni presencia ni ausencia, está entre; sin embargo, es la condición oculta en el sistema de las diferencias.

La diferenzia ${ }^{3}$ no es nunca pura. No se puede convertir en un absoluto... es siempre algo que está entre, está siendo, sin ser ella misma, sin estar nunca presente (Bennington 1991: 91).

Si, según Rousseau (1972: 53), el grito natural es el origen del habla, la escritura tiene como origen la traza (Derrida 1977: 110), que viene, originariamente, a suplir al sonido fónico por razones "de necesidad y de distancia" (1977: 398-9). En este sentido, la escritura es, desde su origen, ausencia, ya que la traza es nada, ni sustancia ni esencia. La escritura de los hombres primitivos era pictórica, luego se transformó a la forma ideo-fono-gráfica actual.

La pintura de los objetos conviene a los pueblos salvajes; los signos de las palabras y de las proposiciones, a los pueblos bárbaros; y el alfabeto, a los pueblos civilizados (Derrida 1977: 415). 
Ahora bien, esta oposición habla/escritura opera dentro del sistema de la cultura. De allí la necesidad de establecer la oposición naturaleza/cultura. La lógica del peligroso suplemento surge cuando la cultura altera lo natural de las cosas y las convenciones se convierten en leyes de carácter tiránico, en una especie de segunda naturaleza convencional, ajena a la naturaleza pura. "El peligroso suplemento destruye a toda velocidad las fuerzas que la naturaleza ha constituido y acumulado lentamente" (Derrida 1977: 216-7). Y se produce la inversión: "La lógica de la suplementaridad quiere que el afuera sea el adentro..." (1977: 308). Lo cierto es que el pasaje del estado natural al estado cultural no obedece a algún movimiento racional, sino a un puro accidente. Lo que Rousseau llama "funeste hasard". Derrida interpreta: "Si las sociedades han nacido de la catástrofe, es que han nacido de un accidente" (1977: 367).

Ahora bien, es indispensable analizar la estrecha relación entre la libertad y la perfectibilidad, dos características innatas de la naturaleza humana. (Lo que hemos representado en la ilustración con agente libre, perfectible). El tema de la libertad ocupa un lugar central en el pensamiento rouseauniano ${ }^{4}$. Despojar a un hombre de esta cualidad moral y metafísica, es como mutilarlo físicamente. Sin embargo, al ser también perfectible por naturaleza, el ser humano está sujeto al cambio, a la evolución, es un ser-siendo, puede avanzar hacia su propia ruina, (la imbecilidad en términos rousseaunianos), creyéndose en la mejor vía de su perfección. He aquí la gran paradoja: la civilización, las ciencias y las artes, la cultura que siempre hemos creído como fuentes de bienestar y de mejoría de la condición humana, se encuentran entrecomilladas y cuestionadas por Rousseau, designadas como fuente de la desgracia, la desigualdad, la angustia y la miseria del hombre. En fin, son sus ataduras ${ }^{5}$.

Rousseau no idealiza el estado de naturaleza. El pasaje del estado natural al estado civil es inevitable, la perfectibilidad lo exige, el hombre no puede quedarse en esa situación de aislamiento. Su sociabilidad es, pues, natural e inevitable. Lo que no es natural, es esta situación creada por el hombre mismo. Cabe recordar que Rousseau es un moralista. La conjugación armónica de la perfectibilidad y de la libertad ocultan un tercer elemento: la responsabilidad. Una de las posibles lecturas o interpretaciones del discurso rousseauniano daría esta combinación: la libertad y la perfectibilidad exigen la conciencia y la responsabilidad de nuestras acciones.

Pero la evolución sin conciencia ni responsabilidad, produjo la inversión del orden natural: la naturaleza deviene suplemento de lo cultural, cuando la cultura no es más que la representación artística de lo natural. Derrida tiene una interpretación concisa al respecto:

Todo lo que es universal, en el hombre, depende del orden de la naturaleza y se caracteriza por la espontaneidad, y todo lo que constriñe a una norma pertenece a la cultura y representa los atributos de lo relativo y de lo particular (1977: 152-153).

Dentro de la dualidad estado natural/estado cultural, el amor tiene dos aspectos. El amor a sí mismo (amour de soi) y el amor propio (amour-propre). Es quizás una particularidad del idioma francés. André Lalande (1980), señala que en inglés hay una sola expresión (Self-love) y subraya que la distinción más precisa se encuentra en Rousseau. El amor a sí mismo es obra de la naturaleza, es el instinto que hace que toda criatura viviente tienda naturalmente a la conservación de sí misma. El amor propio es la forma pervertida del amor a sí mismo; es obra de la razón, de la cultura. Si el amor a sí mismo es natural y universal, el amor propio es un sentimiento relativo, facticio, que lleva a cada individuo a hacer caso de sí mismo en 
detrimento y, a veces en perjuicio, de los demás (cf. nota O, 1972: 153-6). En este sentido, el amor propio es el egoísmo, la vanidad, fuente del honor y fuente de muchos males en la sociedad. Así las cosas, el hombre natural vive por y para sí mismo; en cambio en el estado civil, vive por el qué dirán (le qu'en dira-t’on). El hombre civil, al ser prisionero del amor propio, no es más que una máscara.

En cuanto al amor a secas, tiene también dos aspectos, el amor físico y el amor moral. El amor físico es el deseo; el sentimiento natural y universal que hace que toda persona busque la satisfacción sexual. La parte moral pretende regir el amor mediante normas y convenciones como la familia, con la intención de fijar y regular el amor, o sea, reprimir su impulso natural. Esto hace que la máscara sea cada vez más necesaria para satisfacer el impulso natural del amor. Diríamos, en este caso, que lo cultural, inicialmente como suplemento de la naturaleza, reduce el amor a la suplementaridad, al considerar lo natural como animalidad, o sea, fuera de lo convencional, de lo normal. Surge así otra oposición: animalidad/humanidad.

Lo físico es ese deseo general que impulsa a un sexo a unirse con el otro. Lo moral es lo que determina ese deseo y lo fija en un solo objeto exclusivamente (Rousseau 1972: 65).

En este contexto, hay que hablar de la relación hombre/mujer. Es quizás en esta relación que la lógica del suplemento opera de manera más clara y peligrosa. Desde luego, hay que aclarar que la diferencia sexual es natural; en cuanto a las consideraciones relativas al género, interviene el peso cultural. En palabras de Derrida, la oposición hombre/mujer "no es un fenómeno natural o biológico" (1977: 256). Es un producto de la cultura, considerada originariamente como suplemento de la naturaleza.

En Rousseau, se ve claramente cómo opera el juego de la suplementaridad en la relación hombre/mujer. En Rousseau significa aquí, tanto su experiencia vivida y puesta al desnudo en Las confesiones, como el resto de su obra. En este sentido, Rousseau es un modelo en el que el autor y su obra se funden y no son más que una cosa: un texto.

Así, por ejemplo, en la búsqueda de la jouissance, la habitación de la mujer ausente, incita la imaginación a recurrir al suplemento prohibido: la masturbación. Derrida lo designa como "el auto-afecto sexual" (1977: 223). Madame de Warrens, la primera amante de Rousseau, era a su vez un suplemento de su madre, ausente desde su niñez. Dice Derrida al respecto: "El suplemento mantiene aquí el centro entre la ausencia y la presencia totales" (1977: 226). Al igual que la différance, que no está ni en la ausencia ni en la presencia. "La différance originaria es la suplementaridad como estructura" (1977: 238). Luego, en sus años parisinos, Rousseau dirá: "Je trouvais dans Thérèse le supplément dont j’avais besoin" ("He encontrado en Teresa el suplemento que necesitaba", citado por Derrida 1977: 225). Más claro no se puede. Y en su voluminoso libro sobre la educación, inventa a Sofía como suplemento de Emilio. En el discurso agregado 6 al segundo Discurso, habla de la comunidad femenina como de la otra mitad suplementaria de la república:

¿Podría olvidarme aquí de esa preciosa mitad de la república que hace la felicidad de la otra, y cuya dulzura y cordura contribuyen al mantenimiento de la paz y de las buenas costumbres? Amables y virtuosas ciudadanas, el destino de vuestro sexo será siempre el de gobernar al nuestro (Rousseau 1972: 18-19, cursivas nuestras). 
Desde la perspectiva del género, los términos destacados preciosa, dulzura, cordura, amables, virtuosas y, en el resto del texto, boca de una tierna esposa, belleza, vuestro amable e inocente imperio, persuasiva, suavidad, dulces, corazón, naturaleza, parecen indicar que la mujer, en el estado civil no es tan pervertida y malvada como el hombre civil. ¿Está ella menos alejada del estado natural? Hemos dicho que varios siglos de producción histórico-cultural han reducido lo natural a la animalidad, al margen, en fin, a la secundaridad. Al ser excluida del discurso logocéntrico, la mujer se reduce a la suplementaridad. El término gobernar no está utilizado, en el texto arriba citado, en el sentido político. La res pública, o sea la cosa pública, está en manos de los magistrados y de los ciudadanos, a quienes Rousseau se dirige en la parte titulada "A la República de Ginebra, Magníficos, muy honorables y soberanos señores". La mujer estaba excluida de estas honorabilidades, ya que no era ciudadana. Su papel se reducía a una simple contribución suplementaria, al mantenimiento de la paz. Gobierna al hombre con el corazón, los sentimientos y la persuasiva suavidad. Rousseau lo dice claramente:

Sed pues lo que sois, las castas guardianes de las costumbres y las dulces ataduras de la paz; y seguid haciendo valer, en cualquier momento, los derechos del corazón y de la naturaleza, en provecho del deber y de la virtud (1972: 18-9).

La secundaridad, en este caso, es exclusión y marginalidad, es peligrosa en cuanto altera completamente la obra de la naturaleza. En el estado de la naturaleza, solo había la desigualdad física, la cual era natural. Por desigualdad física se entiende que uno es más grande o pequeño que el otro, lo cual es válido tanto para el hombre como para la mujer, es decir, independientemente de la diferencia sexual. El hombre de la naturaleza es sexífero, a diferencia del Desein heideggeriano que "no sería sexífero". Derrida cuestiona ese silencio de Heidegger sobre la diferencia sexual, lo cual es un silencio que se deja ver, que se deja oír (cf. différence sexuelle, différence ontologique, 1987: 395-414). La diferencia sexual es natural, no es desigualdad. Es en el estado cultural donde la relación hombre/mujer se jerarquiza.

Cabe subrayar que lo imaginario cultural y mitológico profundiza esa jerarquización, al establecer códigos de conducta específicamente femeninos. Dice Derrida: "La parte no es igual y es quizás la significación más profunda del juego de la suplementaridad" (1977: 252). Dicha desigualdad o relación jeraquizada entre el hombre y la mujer no es natural, ya que no tiene origen en el estado de la naturaleza, tal como lo imagina Rousseau. Es una característica fundamentalmente del estado cultural, en donde se jerarquiza todo lo relativo a los términos feminidad/masculinidad, corazón/razón, etc...

Decididamente, a lo que natura no le da, lo cultural le da una estructura imaginaria. Tenía razón Simone de Beauvoir: "On ne naît pas femme, on le devient".

Es así como Derrida plantea la teoría del suplemento a partir de una relectura de Rousseau, cuyo pensamiento dicotómico ofrece un escenario del juego de la suplementaridad por medio de las oposiciones naturaleza/cultura, habla/escritura, centro/margen, hombre/mujer y así sucesivamente, ya que la cadena de suplementos es, por definición, abierta. Esta teoría del suplemento es un gran aporte a los estudios de género. 


\section{La perspectiva femenina como categoría literaria}

Être femme, ce n'est rien, en effet, ni essence ni destin.

Simone de Beauvoir

La mujer, como ente literario, ha sido tema del hombre a lo largo de la historia, puesto que varios personajes de novelas, de renombre mundial, por ejemplo Madame Bovary, han sido creados por escritores de sexo masculino. Más de tres mil años del discurso patriarcal han creado una situación en la que la mujer se encuentra excluida del campo de la reflexión sobre su ser, o mejor dicho, acerca de ella misma. El propósito de algunas críticas feministas es desconstruir, estratégicamente, esta situación y no condición, como producto histórico, con el fin de formular una teoría que posibilite hablar de la mujer desde la mujer, es decir, una nueva manera de abordar el tema de la feminidad, no desde la perspectiva del hombre, sino desde ella misma, como un sujeto consciente, creadora de su propio discurso, de su propia concepción del mundo, de su visión de sí misma.

Ahora bien, al abordar el tema del discurso de la mujer, en su interrelación con el otro, es decir el hombre, surgen varias preguntas: ¿Es la perspectiva feminista propia de la mujer? ¿Puede un hombre apropiarse de la perspectiva femenina? Mona Ouzouf, hablando de Simone de Beauvoir, señala que estas preguntas, entre otras, la preocupan:

Les femmes sont-elles mieux placées que les hommes pour comprendre la situation féminine?

Son sens de l'universel l'incline à penser que non (Ouzouf 1995: 305).

Para Simone de Beauvoir no es necesario ser mujer para comprender la situación de la mujer. Abordar una situación social dada y comprenderla, depende de la actitud del sujeto consciente y del apoyo ideológico y teórico que utiliza. Si se le plantea a la autora de El segundo sexo, ¿por qué las mujeres no tienen acceso al heroísmo, la rebelión, la invención y la creación?, contestaría que no faltan ejemplos de seres de sexo masculino que carecen de proyectos. Para Simone de Beauvoir, la situación de la mujer debe considerarse a nivel más elevado. No se pueden cambiar las cosas sin el cambio del sistema social. La liberación de la mujer pasa por la abolición de las clases sociales. Esta concepción de las cosas se inscribe en la ideología marxista. Además, Simone de Beauvoir está profundamente marcada por la corriente existencialista. Si Sartre subraya que la existencia precede la esencia, Simone de Beauvoir insiste:

Un existant n'est rien d'autre que ce qu'il fait; le possible ne déborde pas le réel, l'essence ne précède pas l'existence: dans sa pure subjectivité, l'être humain n'est rien. On le mesure à ses actes (1976: 401).

Es en este marco general de la filosofía existencialista que concibe el Ser, hombre y mujer, como un sujeto consciente, actuante, libre y responsable, debe entenderse la famosa frase: "On ne naît pas femme: on le devient" (1976: 13, vol. 2). Lo que significa que la mujer no nace predestinada a su situación de marginada, sumisa y subalterna, sino que la sociedad hace que la mujer llegue a ser mujer, un devenir sufrido, en vez de un devenir actuado. La situación de la mujer no es su condición y como toda situación producto de convenciones, es modificable. 
Es importante examinar, con esta base conceptual, cómo la otredad ha construido todo un mito alrededor de Diana Soren. Esa gran actriz no llegó a ser ella misma, sino que llegó a ser lo que el director de cine hizo de ella, lo que el autor de la novela dijo de ella. Existen varios detalles que serán analizados en la sección "La construcción del sujeto femenino".

Hablar de Simone de Beauvoir, como lo hace Toril Moi en Crítica literaria feminista, no tiene sentido. Ni una palabra sobre la corriente existencialista, la sacó de su contexto filosófico e ideológico; abordó El segundo sexo con ligereza, como si se tratara de una autora de una obra única, cuando toda la producción literaria y filosófica de Simone de Beauvoir, así como su rebeldía estratégica en su vida diaria y su combate contra todas las formas de opresión, obedece en verdad a un gran proyecto que se había fijado conscientemente en la vida: ¿Cómo llegar a ser? Toril Moi presentó a Simone de Beauvoir como "una de las mayores teóricas feministas de nuestro tiempo" (1988: 101), sin decir cómo ni por qué. Y trata casi con la misma superficialidad a Luce Irigaray, al no decir nada sobre la lectura del mito de la caverna de Platón, ni las lecturas de Platón a Hegel, temas bien analizados y que ocupan un lugar amplio en la tesis de Irigaray. No es suficiente subrayar "el pesado carácter intelectual" (1988: 106) de la teoría feminista francesa. Se trata más bien de entrarle al discurso patriarcal con todo el bagaje intelectual necesario, cosa que las teóricas francesas, de Simone de Beauvoir a Julia Kristeva, hacen con maestría. De lo contrario, sería difícil lograr el objetivo planteado por Toril Moi al principio de su libro: erradicar "las prácticas machistas" (1988: 10).

Estas críticas no significan que el estudio de Toril Moi sea inútil. Su gran virtud consiste en ofrecer una visión panorámica, casi completa, sobre las dos corrientes de la crítica feminista, las norteamericanas y las francesas. Es un libro fundamental para introducir al principiante al discurso de la feminidad. En este sentido, su libro es un gran aporte. La autora señala con claridad las discrepancias entre las teóricas norteamericanas. Por ejemplo, Showalter acusa a Woolf de ser subjetiva (Moi 1988: 21). Es evidente; no hay una sola perspectiva feminista, sino varias. Además de las dos grandes corrientes, dentro de cada una hay visiones distintas. Existe el feminismo liberal que reivindica la igualdad, el feminismo radical que rechaza el orden simbólico masculino y el feminismo que niega la dicotomía masculino-femenino. Lo cierto es que cada visión feminista aporta su grano de arena para comprender la feminidad.

La literatura feminista tiene como principales preocupaciones estudiar lo que caracteriza la autoría femenina, la escritura de mujeres y sobre las mujeres. Pero los estereotipos de la feminidad que señala Mary Ellmann: indecisión, pasividad, inestabilidad, confinamiento, piedad, maternidad, espiritualidad, irracionalidad, complicación y la figura de la Bruja y la Arpía (citado por Moi 1988: 47), pueden ayudar a cualquiera, independientemente de su sexo, hombre o mujer, a leer un texto dado, sin ser necesariamente literatura de mujeres. Tales estereotipos se ven claramente en la construcción de Diana de Carlos Fuentes.

En la novela de Carlos Fuentes se nota también el pensamiento binario machista, que analiza Hélène Cixous (Moi 1988: 114):

MUJER

Pasividad

Luna

Naturaleza

\section{HOMBRE}

Actividad

Sol

Cultura 


$\begin{array}{ll}\text { Noche } & \text { Día } \\ \text { Madre } & \text { Padre } \\ \text { Corazón } & \text { Cabeza } \\ \text { Sensible } & \text { Inteligible } \\ \text { Pathos } & \text { Logos }\end{array}$

A la luz de esta dicotomía, es importante señalar dónde está Diana y dónde está su amante, Carlos Fuentes. Es también de gran interés subrayar la lucha por la supremacía, es decir, por el poder, en la relación entre ellos dos. El abordaje de la novela, desde la perspectiva feminista, permite ver esta realidad binaria, claramente expuesta por el autor, producto y víctima, al igual que Diana, de la cultura machista.

Diana se sitúa en la "lógica suplementaria", otro gran concepto que constituye el eje teórico de esta lectura de Diana o la cazadora solitaria. Emilia Macaya, a partir de Derrida, analiza cómo opera la lógica del suplemento en la categoría del género.

En el género, por ejemplo, los términos hombre-mujer, masculinidad—feminidad, ocultan igualmente una jerarquización tras su cara de falsos opuestos (1992: 5).

Resulta de gran interés confrontar la lógica del suplemento con la situación planteada en Diana o la Cazadora solitaria. La protagonista está excluida de los tres niveles de creación "el divino, el político y el artístico" (Macaya 1992: 3). Aunque Diana sobresale en estos tres niveles, el lenguaje machista y la forma de construir el discurso ocultan esta realidad. A la luz de la perspectiva feminista, es posible enfocar la atención en las zonas ocultadas del discurso, para así elucidar el papel protagónico de Diana.

En síntesis, si una novela se puede leer desde la perspectiva marxista, psicoanalítica, existencialista, desde la concepción dialógica y la intertextualidad de Bajtin, para cualquier investigador, independientemente de su sexo, es evidente, igualmente, que la categoría del género puede ser un recurso de análisis literario, sin importar el sexo del investigador. Es más, si "una mujer que imita el discurso del hombre es sencillamente una mujer que habla como un hombre" (1988: 151), según la crítica que hace Toril Moi a Irigaray, un hombre puede de igual manera imitar el discurso femenino. Por consiguiente, tanto el hombre como la mujer pueden leer una obra literaria desde la perspectiva feminista.

\title{
3. Un lenguaje de tinte machista
}

\author{
Hombres necios que acusáis \\ a la mujer sin razón, \\ sin ver que sois la ocasión \\ de lo mismo que culpáis \\ Sor Juana Inés de la Cruz
}

Diana o la cazadora solitaria es una novela autobiográfica, una crónica y casi una confesión, cuyo tema es el adulterio, el sexo sin compromiso alguno. Carlos Fuentes narra su aventura amorosa con la actriz norteamericana Diana Soren ${ }^{7}$, durante su estadía de dos meses 
en México, para el rodaje de una película. En la narración, se nota la sinceridad del autor, al decir algunos detalles que no le convienen: "Quiero ser muy franco en este relato y no guardarme nada" (1994: 22). Fuentes vivía con su primera esposa llamada en el texto Luisa Guzmán, que amaba "por su belleza y su sencillez" (1994: 27). No es la primera vez que engaña a su mujer. Había una especie de contrato entre ellos dos. Se deja llevar por sus tentaciones donjuanezcas y su esposa lo esperaba quieta: "Todo me lo perdonaba; yo siempre había regresado. Ella era el remanso, la laguna quieta donde yo podía escribir" (1994: 29).

En aquella noche de la fiesta del fin de año, el 31 de diciembre de 1969, todas las mujeres presentes eran identificadas como esposa de alguien, excepto una llamada La China, que tenía su identidad propia, no por su origen chino, sino por ser escritora. Desde el primer contacto entre los ojos de Carlos y los de Diana, nació una pasión desenfrenada. Poco después, Diana decidió ir a Santiago para comenzar su trabajo. Es llamativo que el autor describe así la escena: "Ella se adelantó. Decidí seguirla" (1994: 49). La verdad, es que él estaba enloquecido por la belleza de Diana; no estaba en posición de decidir nada, ella sí decidía, él no hacía más que seguirla. Pero la tradición machista hace que el hombre sea quien decida y la mujer siga obediente. Es más, la idea de la pertenencia de la mujer al hombre está claramente dicha: "En el estudio, dejaba de pertenecerme. Se adueñaban de ella las peinadoras, las maquillistas, las vestidoras" (Fuentes 1994: 47-8). Ella no pertenece a sí misma, en París es esposa de un famoso escritor, en su viaje a México pertenece a su amante Carlos Fuentes de noche y de día, al director de cine; cuando hizo por vez primera el amor a la edad de 14 años, en su ciudad natal Jeffersontown, lo hizo "completamente, vaginalmente, con un hombre" (1994: 87).

Para poseerla como una cosa, como un objeto sexual, Fuentes le propuso dejar su trabajo de actriz, "dejar todo, que viniera conmigo a uno de los puestos universitarios norteamericanos que a veces me ofrecían" (1994: 87). He aquí una actitud machista. El autor piensa sólo en su propia realización, sin importar la de su amante. Es que Diana era una mujer muy erótica, pareciera vivir para el sexo, hacía todo para agradar y satisfacer a su amante. Al meter la nariz en su vagina, en la posición 69, se dio cuenta de un producto excéntrico: "la crema vaginal con sabor a fruta" (1994: 46). En esa relación pasajera, todo era permitido, lo que aumentaba la jouissance sexual.

La pedí felación cuando intuí que ella quería mamar verga, que agarrarla de la nuca y acercarla a mi pene levantado como a una esclava dócil era el placer que queríamos los dos (Fuentes 1994: 102).

Si bien el éxtasis erótico descrito en varias escenas tiene como propósito la satisfacción de los dos, lo que podría llevar a una deducción engañosa de una igualdad entre ambos sexos, el lenguaje utilizado no deja la menor duda sobre la creencia en la supremacía del macho en la relación erótica. El dominio del macho está clarísimo con el tono de los términos: "agarrarla... acercarla... como a una esclava dócil". No hay, pues, una relación de igualdad entre dos sujetos conscientes que hacen el amor. Estos términos indican más bien una relación sujeto-objeto.

Cuando nació la confianza entre ellos, comenzó a tratarla de chiquilla: "No le gustaba que la llamara gamine como empecé a hacerlo" (1994: 43). Poco después, Carlos Fuentes va más lejos en el desprecio de su amante. Resulta que Diana tenía miedo de las puertas abiertas, todas debían estar cerradas, incluso la del baño. Sin embargo, dejaba abierta la ventana 
para ver la luna. Aunque el autor no omite esa escena romántica, con una mujer tan erótica y bella sobre la cama, contemplando la luna, su machismo lo hace pensar en manías irracionales, y utiliza otra vez el verbo decidir para significar su poder:

Decidí no darle gusto a sus manías irracionales, la puerta del baño siempre cerrada, las cortinas de las ventanas siempre apartadas, esperando que entrara la luz de la luna sobre un paisaje nevado... Pero yo vivía, en ese momento, una ansia de poder sobre las mujeres desgarrada por la vanidad y el capricho; excluía la vanidad y el capricho de la mujer, los eliminaba y a veces las eliminaba a ellas si no obedecían mi voluntad de eliminar sus propios caprichos (1994: 141).

Más adelante, expresa el machismo mexicano, y aún latinoamericano, en una especie de autoanálisis psicológico, siempre comenzando por el decidir que marca la voluntad del macho. Es también un intento de justificar su machismo:

Había decidido que ninguna mexicana adquiriese poder sobre mí mediante el capricho, la vanidad, el orgullo. Me adelantaba a ellas, les daba una sopa de su propio chocolate. Me había herido demasiado de joven, eran débiles, vanidosas, fáciles de convencer cuando sus padres me borraban de las listas de maridos elegibles por la simple razón de que yo ni tenía dinero y mis rivales sí (1994: 142).

Pero con Diana, su estrategia de adelantarse a la mujer no le funcionó. Tenía que regresar a la Ciudad-México, por unos días. Su esposa estaba muy herida y callada. Pues, en un monólogo interior, trataba de imaginar el pensamiento de su mujer:

Estás dejando de ser persona. Mientras lo fuiste, respeté tus amoríos. He acabado por entender que no te respetas a ti mismo. No respetas a las mujeres con que te acuestas. Las usas como pretexto literario. Y me niego a seguirlo siendo (1994: 179).

Luego de un silencio pesado, ese silencio-enunciado, lleno de reproches y de significado, Carlos Fuentes dijo a su esposa: "— Es tu culpa. Debiste poner un hasta aquí desde la primera vez que me fui con otra" (1994: 179). ¿Es culpa de quién en verdad? Dejó a su mujer por otra mujer y es culpa de la mujer. La mujer es siempre la culpable desde antes de aquel mito bíblico:

Estaban ambos desnudos, el hombre y su mujer, pero no se avergonzaban uno del otro... Yahvéh Dios llamó al hombre y le dijo: "... ¿Has comido acaso del árbol del que te prohibí comer? Dijo el hombre: "La mujer que me diste por compañera me dio del árbol y comí"... A la mujer le dijo: "Tantas haré tus fatigas cuantos sean tus embarazos: con trabajo parirás los hijos. Hacia tu marido irá tu apetencia, y él te dominará" (Biblia de Jerusalén, Génesis 2, 25 y 3, 1-16).

El hombre es el eterno inocente, la mujer es tentación y culpa. He aquí uno de los orígenes del lenguaje de tinte machista.

En el tren que lo llevaba de regreso a Santiago, para encontrar de nuevo a la "dulce y dócil" Diana, él preparaba, en un monólogo interior, un plan para dejarla:

¿A dónde se iría Diana, a dónde yo? ¿Seguiríamos juntos? Lo dudaba. En París la esperaba su marido. En Los Ángeles, un Pantera Negra con el que habla por teléfono a las tres de la mañana. En Jeffersontown, un novio idealizado... Yo era su amante porque no dejaban entrar a México a su verdadero lover, el líder de los Panteras Negras. ¿Debía yo adelantarme a un desaire, 
anticipar la ruptura, ser yo quien tomara la iniciativa de romper con ella, antes de que ella, más que romper, abandonara, dejara, olvidara lo nuestro? (1994: 181-2).

Todo esto indica un donjuanismo femenino en la figura de Diana. Es más, en París, durante los últimos años de su vida, andaba en los bares en busca de jóvenes que le gustaban. Razón por la cual, su marido confió a Carlos Fuentes, muchos años después, sin saber que era su rival:

No se dio cuenta de que una cosa llevaba a la otra. ¿Ves?, la rebeldía al exceso sexual y éste al alcohol y el trago a la droga y la droga al terror, a la violencia, a la locura (1994: 211).

Es bien sabido, en la sociedad patriarcalmente concebida, que un hombre que ande detrás de las mujeres, es un seductor exitoso, un Don Juan, ¿y qué?; pero si una mujer hace lo mismo, la tratan de "loca y de puta". Para volver a la ruptura con Carlos Fuentes, para sorpresa suya, durante su ausencia, ella había decidido escoger a otro amante y nada más y nada menos, que al estudiante Carlos Ortiz, que el autor había presentado como un personaje muy secundario, casi inútil. Y helo aquí como un rival potente. Entró en una crisis de celos cuando Diana le lanzó en la cara: "Perdóname. Tengo otro amante" (1994: 211). El plan de Carlos Fuentes fracasó. No tomó la iniciativa de romper con ella. Ella lo hizo primero. El otro se sentía humillado, aunque sabía que se trataba de una aventura pasajera; lo duro fue que ella se le adelantó al decidir la ruptura. Durante esta aventura, casi en todas las ocasiones, ella era el centro de la decisión, la que tomaba la iniciativa; él no hacía más que seguirla. Aunque parecía sumisa y dócil, en el fondo tenía un tremendo poder. No obstante, el lenguaje machista ocultaba esta realidad.

Para concluir, no cabe analizar todos los signos lingüísticos patriarcales de la novela y sería fastidioso citar al pie de las páginas los calificativos utilizados, no sólo para referirse a Diana, sino a otras amantes, a la mujer en general. Al menos, he aquí la lista de algunos calificativos encontrados a lo largo de la novela: "perversa, divina, santa, esposa, amante, gamine, niña bien insoportable, débil y dulce, famosa, maravillosa, belleza y sencillez, vanidosa, fácil, esclava dócil, erótica, bruja, loca, extraña, culpable, frágil y destruible, manías irracionales, paranoica, maternidad, puta, locura..."

\title{
4. Construcción del sujeto femenino
}

\author{
Au lieu où j'aurais lieu d'être, se trouve, au \\ présent le néant. Et si je n’y prends garde, je suis \\ réduite à l'état d'objet-ustentil.
}

Luce Irigaray, Passions élémentaires

Hablar de un sujeto es hablar de una conciencia, de su identidad en dos perspectivas: como la concibe el sujeto mismo y como la concibe la otredad; es decir, tal como el sujeto se identifica, y como los demás lo identifican. Ese diálogo corto entre Carlos Fuentes y Diana es revelador: "Yo sé quién soy", dice Diana. "¡No sabes!", gritó Carlos Fuentes (1994: 189). Se le ha negado el derecho de crear su propia imagen ${ }^{8}$, de decir su concepción de sí misma. Ella no es ella desde ella misma. Es lo que los demás dicen de ella. Son escasos los pasajes en donde habla de ella misma, por lo que se analizará aquí la identidad de Diana vista por la otredad. 
Desde el título, el autor asocia a Diana Soren con la figura de la mitología griega: Diana la Cazadora. Al principio de la novela, identifica a su personaje con la hija de Zeus, gemela de Apolo:

Diana, Diana Soren. Su nombre evocaba esa ambigüedad antiquísima. Diosa nocturna, luna que es metamorfosis, llena un día, menguante al siguiente, uña de plata en el cielo pasado mañana, eclipse y muerte dentro de unas semanas (1994: 13).

A lo largo del relato, se ve esa ambigüedad del personaje: Diana amada, en una perpetua búsqueda de nuevos amores, porque como dice Emilia Macaya: "Diana representa, al mismo tiempo, la atracción erótica y el rechazo del amor" (1992: 55). Pero esa construcción del personaje femenino sobre la base de un mito es significativo, ya que el mito según Cassirer:

Es la simplicidad misma, pues no se trata sino de la sancta simplicitas del género humano. No es el producto de la reflexión o el pensamiento, ni basta con describirlo como resultado de la imaginación humana... El responsable de esos absurdos y contradicciones sería más bien la Urdummheit del hombre. Sin esta "primitiva estupidez" no existiría el mito (1974: 9).

Esta asociación no es ingenua, desde el principio se presenta un personaje femenino ambiguo, ajeno a lo lógico, lo racional, características propias del hombre. Esta construcción del sujeto femenino está estrechamente conforme al pensamiento binario que señala Hélène Cixous, así como a los estereotipos de la mujer que examina Mary Ellmann: Diana, nocturna, luna, naturaleza, complicación, irracionalidad... en fin, toda una sencillez rodeada de misterios como la oscuridad de la noche.

El autor asocia a Diana también con otro personaje femenino subversivo, Juana de Arco: "La escogieron para hacer el papel de la Santa Juana de Shaw entre dieciocho mil aspirantes" (1994: 78). Aquella revolucionaria que daba órdenes al Rey de Francia e intentaba combatir al ejército británico. Dice Fuentes: "Era una mujer vestida de hombre: irritaba al machismo feudal" (1994: 79). Le cayó todo el poder de la corona encima. ¿Cómo no eliminarla, quemarla viva? En opinión de Shaw: "Juana fue como Sócrates y Cristo. La mataron sin que nadie levantara un dedo para defenderla" (1994: 79). ¿Tendrá Diana Soren el mismo destino que Juana de Arco?

Antes de contestar la pregunta, hay que seguir el hilo de la construcción de este sujeto femenino desde la otredad. Para sus padres, era una mujer "extraña, sofisticada" (1994: 90). Para su marido, una mujer terriblemente complicada. Así se ve en lo que confió a Fuentes: "Es que tú no conociste la dificultad de amar a una mujer a la que no puedes ni ayudar, ni cambiar, ni dejar" (1994: 209). ¡Ah!, si el pobre marido supiera que Carlos Fuentes fue su rival alguna vez. Para el director de cine era una actriz rebelde, difícil de controlar, de dominar. En palabras de Diana:

Para salir de la tiranía del director, me casé con un escritor ilustre que podía dominar al mismísimo director y a todos los estudios de Hollywood (1994: 81).

Para el autor, además de su fascinación ante la belleza de Diana, tal como lo demuestran las descripciones de su cuerpo y de su habilidad erótica, encontró en ella una excelente figura convertible en un personaje literario. La sinceridad del autor no deja lugar a sombras: 
"Sexo, política, alma, todo pasa para mí por la experiencia literaria" (1994: 107). Es significativo ver que para conocerla no se dirigiera a ella, sino a la foto de Clint Eastwood, su examante, que Diana había puesto en su cuarto en "las narices" de Fuentes. Ese recurso a la otredad para descubrir el sujeto femenino se ve aún más claro en este pasaje:

Quise convencerme, perversamente, de que la única manera de amar a una mujer es saber cómo la amaron, qué dicen de ella y cómo son todos los hombres que la quisieron antes que yo (1994: 54).

Ese qué dicen de ella merece reflexión: ella no es ella, sino lo que dicen de ella. Se ha examinado lo que piensan de ella sus padres, su marido, el director de cine, el autor como amante... etc. He aquí cómo la mujer llega a ser mujer. El peso de más de tres mil años de la concepción de la mujer en lo mitológico, lo cultural, lo literario que señala Simone de Beauvoir es fundamental para comprender la construcción del sujeto femenino.

Se ha analizado la identidad de Diana desde múltiples voces que le son ajenas. Desde ella misma poco se sabe. Su interior es incógnito. Hay que recurrir a la reflexión y a la deducción para descifrar su silencio. Es llamativo su gusto por repetir versos como: "You can't go home a gaine... Who takes care of me..." ¿Se sentía sola? ¿Necesitaba protección? Es justamente lo que buscaba, compañía y protección, en su marido, en sus padres, en sus amantes, en sus semejantes. A fin de cuentas, el autor se desdice:

La vi, con la pequeña distancia ganada, como una mujer que sí sabía, finalmente, quién era. Una extranjera en todas partes, condenada a la soledad y al exilio (1994: 198).

Si bien es cierto, eso no lo dice Diana. Es lo que el autor-amante dice de ella.

Ser figura pública no es siempre una ventaja. Diana Soren sobresalía en los tres niveles de creación reservados al hombre, según la concepción del mundo patriarcalmente concebido. En lo divino se le llamaba la Santa, por haber interpretado el papel de Santa Juana de Arco. En lo artístico, era una actriz estrella de Hollywood, a pesar de la tiranía del director de cine. En lo político, se expresó abiertamente contra la guerra de Vietnam y ayudaba con grandes cantidades de dinero a los Panteras Negras que luchaban por los derechos políticos de la comunidad negra en los Estados Unidos de los años 60. Al igual que Martín Luther King y Malcom X. Aunque utilizaban distintos métodos de rebelión, tenían un propósito común: la denuncia de la exclusión y la marginación y clamaban por la justicia y la igualdad racial.

Si para el gran público Diana Soren era una actriz respetada, con su arte, su belleza, su dinero y sus ideas, para el FBI, la Agencia más poderosa en toda la historia del poder, Diana era vista así: "Famosa, bella, blanca, Santa Juana de las causas radicales" (Fuentes 1994: 202). Esa ayuda a los negros, que pretendían la igualdad con los rubios blancos, molestaba a Washington. Pues, había que eliminarlos, comenzando por las cabezas. A Martin Luther King y Malcolm X los asesinaron como héroes en lucha. A Diana, le cayó encima el aparato propagandístico del FBI, golpeándola en la parte más intima, más sagrada de la mujer: la maternidad. Dice Emilia Macaya: "En nuestra civilización occidental, la imagen de la feminidad ha sido absorbida por la maternidad" (1992: 88-9). Nadie puede dudar de la maternidad. En cuanto a la paternidad, puede haber dudas. Diana quedó embarazada en México. El bebé murió a los tres días de haber nacido en París. Según Carlos Fuentes: "Blanco no es. Negro tampoco" 
(1994: 206). ¿Quién era el padre? ¿Carlos Fuentes? ¿Carlos Ortiz? El autor se defiende, con su poderosa pluma:

¿Era yo el padre? No lo creo. Nuestras precauciones siempre funcionaron. ¿Lo era entonces el joven Carlos Ortiz, mi sucesor en los favores de Diana? Esto era más posible (1994: 203).

Tenía razón Sartre: "La desgracia, es siempre el otro". Para el FBI, la cosa era más simple, había llegado la ocasión de destruir a la Santa Juana de las causas radicales: el padre de ese niño canela era un Pantera Negra. Y corre el ruido de la calumnia, del chisme. Diana se vio obligada a volar de París a Estados Unidos para exhibir el cadáver de su hijo ante las cámaras indiscretas de los periodistas y al público en Jeffersontown, para mostrar su color. Según Carlos Fuentes:

La cólera de Diana era contra la manipulación política de su sexo. El FBI la reducía a un objeto sexual. La presentaba como una mujer blanca hambrienta de un hombre negro (1994: 206).

Ese golpe a la maternidad es muy significativo. El FBI había bien preparado su veneno mortal. Diana nunca pudo reponerse de esa calumnia. Se libró al alcohol, la droga y el sexo, hasta que un día la encontraron en estado de putrefacción en su carro en París, con una carta de suicidio.

Muchos años después, para escribir su relato, con la intención de reivindicar la dignidad y la memoria de Diana, Carlos Fuentes comenzó la investigación, tras los pasos de la que fue una vez su amante. Según la secretaria de la actriz, Azucena, que la había acompañado en México y a todas partes, Diana una vez salió del baño, en el aeropuerto Kennedy,

desnuda, gritando y corriendo a lo largo del pasillo... Quería mantenerse delgada para volver a filmar. Las dietas rápidas la debilitaban y la enervaban... Entró y salió de varias clínicas

(Fuentes 1994: 213).

Sola, humillada, deprimida, psicológicamente destruida; es así como la calumnia y la indiferencia la enloquecieron. Finalmente, la única que habló de Diana como de un ser humano normal fue Azucena: "La verdad es que Diana sufrió mucho" (Fuentes 1994: 215). Con esa voz femenina termina la construcción del sujeto femenino, Diana Soren, según lo imaginario de la otredad. Queda mucho por decir, muchas interrogantes sin respuestas, muchas zonas oscuras ocultadas por el lenguaje machista y muchas dudas, porque sencillamente ella no tuvo la oportunidad de decir su versión, su propia verdad. 


\section{Conclusión}

Una mujer lanzada detrás de una venganza sería capaz de cambiar el destino. La mujer es infinitamente más mala que el hombre, y es también mucho más lista.

Nietzsche, Ecce homo

Se ha intentado leer como mujer, sin necesidad de hacer una metamorfosis misteriosa o alguna cirugía en el órgano sexual, ya que el problema no es el sexo, que es natural, sino el género, que es cultural. Es cuestión de utilizar la perspectiva femenina como método de análisis literario. Ello permite enfocar las zonas ocultadas por el discurso patriarcal, las cuales escapan a otros recursos metodológicos. Otro argumento: si existen mujeres que leen como hombres, por haber asimilado la lógica del discurso machista, el hombre igualmente puede leer como mujer, si asimila la perspectiva femenina. Ahora bien, una cosa es utilizar un método, otra es creer en un fin más elevado, es decir, hacer las cosas con convicción. Es evidente que la perspectiva femenina ofrece una posibilidad de tener una visión diferente de la humanidad, por lo que la voz de la mujer ha de incluirse, no solo en las técnicas de análisis literario, sino en todos los campos del conocimiento.

Se ha analizado el lenguaje machista y la construcción del sujeto femenino en la novela objeto de estudio, a la luz del discurso de la feminidad. Este estudio evidencia que la mujer está marginada y discriminada. Aún sobresaliente en los tres niveles de creación, como lo fue Diana Soren, gran artista, asociada a una santa, con ideas claras de justicia al ayudar a la integración de la comunidad negra, no escapa a la lógica del suplemento. A la mujer que intenta invertir el orden establecido, la declaran culpable. En nuestra sociedad machista hay discriminación hacia la mujer hasta en el castigo, ya que a los líderes de la causa de la igualdad racial los asesinaron como héroes, mientras que a Diana la calumniaron con bajeza en su maternidad. La mataron, utilizando la fuente de la vida.

Aunque Simone de Beauvoir piensa que no es necesario ser mujer para comprender la situación de la mujer, el testimonio de Azucena, la secretaria de la actriz, la única que ha hablado del sufrimiento de Diana, evidencia que, dado el peso de la cultura patriarcal, actualmente, la mujer entiende mejor que el hombre la situación de la mujer.

Para erradicar las prácticas machistas se necesita una nueva cultura, un cambio en las mentalidades; todo un proyecto por hacer. Y se está haciendo, ya que existen mujeres rebeldes contra el discurso machista. Es preciso tomar en cuenta las voces femeninas. Pero no hay que creer que solo la mujer es víctima del sistema patriarcal, el hombre también es víctima del sistema de pensar creado por él mismo. Ahora bien, es obvio que el grado de sufrimiento no es el mismo para el oprimido que para el opresor.

Simone de Beauvoir fue invitada una vez por un club de mujeres en Estados Unidos. Luego dijo: "Esa cena entre mujeres es una triste cena sin hombres" (citado por Ouzouf 1995: 310). Eso significa que el destino del hombre y de la mujer es vivir juntos, en búsqueda de la felicidad, sin jerarquización basada sobre la diferencia sexual. Porque la dominación de uno implica necesariamente la sumisión del otro y la sumisión es esclavitud generadora de la rebeldía y de la violencia. Nuestra cultura ha creado dos seres ajenos uno al otro, cuando nuestro destino es cohabitar poéticamente y en armonía. Dicha situación imposibilita la felicidad, 
que es el fin de la vida humana. Es bien sabido, desde los filósofos griegos, que el ser humano, por naturaleza, busca su bienestar y su felicidad, no como un individuo abandonado a su suerte en un desierto, sino en la Polis, es decir, con los demás. Esa convivencia del Yo con el Otro requiere de un descubrimiento mutuo, mediante la voz femenina y la voz masculina, en condiciones de igualdad. De lo contrario sería difícil lograr la felicidad. Y no es otra cosa lo que clama la filósofa Simone de Beauvoir, más de veinte siglos después de los griegos, con su famosa frase: "Le bonheur mon unique affaire" (citado por Ouzouf 1995: 296). Una felicidad no como dependiente de alguien o suplemento de nadie, sino como un sujeto consciente, un sujeto actuante, libre y responsable de su propio devenir.

\section{Notas}

1. Tal es el fin del capítulo VIII del libro IV del Contrato Social

2. ¿Por qué el hombre es el único que está sujeto a volverse imbécil?", se pregunta Rousseau en el segundo Discurso (1972: 46).

3. Nota de la traductora Ma. Luisa Rodrígez: "En francés se pronuncia exactamente igual différence = diferencia y différance, término relacionado con el anterior pero también con el verbo différer $=$ diferir, postergar. Hemos optado por traducir différance por diferenzia al ser también una cuestión de escritura, la z, lo que distingue este término de diferencia" (Bennington 1991: 91).

4. En el segundo Discurso designa al hombre como un "agente libre", el Contrato Social comienza por el tema de la libertad, todo el proyecto educativo de Emile se basa sobre la libertad, en el Proyecto de Constitución para Córcega y Consideraciones sobre el gobierno de Poloña propone la libertad de los pueblos.

5. Tal es el punto de partida del Discurso sobre las ciencias y las artes y, en gran medida, la segunda parte del Discurso sobre el origen de la desigualdad entre los hombres.

6. Esta parte se agregó después del rechazo de la Academia de Dijon.

7. Jean Seberg era el nombre real de la actriz norteamericana con quien Carlos Fuentes tuvo una relación amorosa. El autor cambió algunos nombres, otras personas aparecen con sus nombres reales, por ejemplo, Luis Buñuel, la escritora Hélène Cixous, que el autor presenta como "una amiga maravillosa" (1994: 181).

8. Toril Moi es clarísima sobre el asunto: "A las mujeres se les niega el derecho de crear sus propias imágenes de feminidad, y se ven, en cambio, obligadas a conformarse con los modelos machistas que se les imponen" (1988: 68).

\section{Bibliografía}

Beauvoir, Simone de. 1976. Le deuxième sexe. París: Edition Gallimard/folio.

Bennington, Geoffrey y Jacques Derrida. 1991. Jacques Derrida. Traducción de Ma. Luisa Rodríguez. Madrid: Edición Cátedra. 
Cassirer, Ernst. 1947. El mito del Estado. México: F.C.E.

1984. "L’unité dans l’oeuvre de Rousseau". Pensée de Rousseau (comp. Tzvetan Todorov). París: Edition du Seuil, 41-65.

Derrida, Jacques. 1977. De la grammatologie. París: Edition de Minuit.

1987. Psyché. Invention de l'autre. París: Edition Galilée.

1994. Márgenes de la filosofía. Madrid: Edición Cátedra.

1996. La desconstrucción en las fronteras de la filosofía. Introducción de Patricio Peñalver. México: Ediciones Paidós.

Dolto, Françoise. 1982. Sexualité féminine: libido, érotisme, frigidité. París: Edition le Livre de Poche.

Fuentes, Carlos. 1994. Diana o la cazadora solitaria. México: Edición Alfaguara.

Hellerman, M. Kasey. 1974. "The Coatlicue-Malinch conflict: A mother and son identity crisis in the writing of Carlos Fuentes". Hispánica. 57(4). Illinois University. 868-75.

Kristeva, Julia. 1981. Le langage, cet inconnu. París: Edition du Seuil.

Lagmanovich, David. 1975. "Las cuatro Helenas de "Las dos Helenas" de Carlos Fuentes: Una escala de ambigüedad". Cuadernos hispanoamericanos. (295). Madrid. 162-8.

Lalande, André. 1980. Vocabulaire technique et critique de la philosophie. París: Presses Universitaires de France.

Macaya, Emilia. 1992. Cuando estalla el silencio: para una lectura feminista de textos hispánicos. San José: Editorial de la Universidad de Costa Rica.

Moi, Toril. 1988. Crítica literaria feminista. Madrid: Edición Cátedra.

Muchnik, Nicole y Carol Kehringer. 1984. De Sartre a Foucault. (Entrevistas, específicamente: "Derrida, l'insoumis", "Jean Genet chez les Pantheres noires", "Sartre et les femmes", "Foucault: non au sexe roi", "Beauvoir par elle-même", "Deux heures dans la vie de Catherine Deneuve"). París: Edition Hachette.

Ortiz, Julio. 1995. Retrato de Carlos Fuentes. Barcelona: Edición Círculo de Lectores.

Ouzouf, Mona. 1995. Les mots des femmes. París: Fayard.

Potevin, Claudine. 1984. "La política del macho en "La muerte de Artemio Cruz". NS Canadian Journal of Latín American and Caribbean studies. 9 (17): 63-74. 
Rousseau, Jean-Jacques. 1943. Du contrat social. Introducción, notas, comentario de Maurice Halbwachs. París: Edition Montaigne.

1966. Du contrat social. París: Edition Flammarion.

1966. Emile ou de l'éducation. París: Edition Flammarion.

1971. Discours sur les sciences et les arts, seguido de Discours sur l'origine et les fondements de l'inégalité parmi les hommes. París: Edition Flammarion.

1972. El origen de la desigualdad entre los hombres. Traducción de Coloma Lleal. México: Edición Grijalbo.

Todorov, Tzvetan. 1977. Théorie du symbole. París: Edition du Seuil. 